\title{
Craniectomía descompresiva en una paciente con encefalitis herpética asociada a hipertensión intracraneana refractaria
}

\author{
Patricio Mellado $\mathrm{T}^{\mathbf{1}}$, Luis Castillo $\mathrm{F}^{2,5}$, \\ Max Andresen $\mathrm{H}^{3,5}$, Manuel Campos $\mathrm{P}^{4}$, \\ Carlos Pérez $\mathrm{C}^{3}$, René Baudrand $\mathrm{M}^{5}$. \\ Decompressive craniectomy in a \\ patient with an herpetic encephalitis \\ and refractory intracranial \\ hypertension
}

\begin{abstract}
Herpetic encephalitis is the most common cause of viral encephalitis in our country. Pathological studies show progressive necrosis and edema in specific territories of the brain. The mortality of herpetic encephalitis was reduced from $70 \%$ to $20 \%$ with the use of intravenous aciclovir in the first three days of illness. However, almost $50 \%$ of patients develop a neurological deficit. One of the most important causes of death in herpetic encephalitis is the refractory intracranial hypertension. There are anecdotal reports of patients with refractory intracranial hypertension due to herpetic encephalitis that were treated with decompressive craniectomy with good results. We report a 21 years old female patient with herpetic encephalitis and refractory intracranial hypertension that was successfully treated with a decompressive craniectomy (Rev Méd Chile 2003; 131: 1434-8).
\end{abstract}

(Key Words: Craniectomy; Encephalitis, viral; Herpes simplex)

Recibido el 30 de junio, 2003. Aceptado el 4 de agosto, 2003.

Departamentos de Neurología ${ }^{1}$, Anestesiología ${ }^{2}$, Medicina Interna ${ }^{3}$, Neurocirugía ${ }^{4}$, Programa de Medicina Intensiva ${ }^{5}$ y Residente de Medicina Interna ${ }^{5}$, Facultad de Medicina, Hospital Clínico de la Pontificia Universidad Católica de Chile.

L a encefalitis herpética $(\mathrm{EH})$ es la encefalitis viral más frecuente en nuestro país ${ }^{1}$. Su mortalidad se redujo drásticamente con la introducción del aciclovir intravenoso en la década de 1980$89^{2,3}$, sin embargo, su mortalidad persiste en $20 \%$

Correspondencia a: Dr. Patricio Mellado T. Marcoleta 347, Santiago. Santiago-Chile. E mail: pmellado@med.puc.cl. Fax: 56-2-632-6221. y su morbilidad en $50 \% 1,4,5$, debido fundamentalmente a hipertensión intracraneana refractaria al tratamiento médico.

Presentamos el caso de una paciente con EH que inició tratamiento con aciclovir tardíamente y que desarrolló una hipertensión intracraneana refractaria al tratamiento médico. La paciente fue sometida a una hemicraniectomía descompresiva con resultados favorables. 


\section{Caso CĹ́NICO}

Paciente de 21 años sin antecedentes mórbidos que se presentó con un cuadro clínico de tres días de fiebre, cefalea, mialgias y alucinaciones olfatorias. Fue ingresada a un hospital terciario pesquisándose signos meníngeos, sin compromiso de conciencia ni focalización neurológica. Se realizaron dos punciones lumbares (tercer y quinto día de evolución) (Tabla 1). El estudio microbiológico del líquido cefalorraquídeo (LCR) fue negativo. Se inició tratamiento antibiótico empírico con ceftriaxona. Al sexto día del inicio de los síntomas presentó una convulsión tónico-clónica generalizada y se inició tratamiento anticonvulsivante con fenitoína. Al octavo día se comprometió la conciencia progresivamente, apareció anisocoria (midriasis arrefléctica derecha) y desviación de mirada conjugada a derecha. Se decidió traslado a la unidad de tratamiento intensivo de nuestra institución.

Ingresó a nuestro hospital al octavo día de evolución, hemodinámicamente estable, febril $\left(38,5^{\circ} \mathrm{C}\right)$, intubada y ventilando espontáneamente. En el examen físico destacaba sopor profundo, pupilas isocóricas y reactivas, rigidez de nuca y hemiparesia braquio-crural izquierda. Se realizó una tomografía computada de encéfalo (TAC) que mostró una extensa lesión hipodensa basal bifrontal y témporo-parietal derecha, con hernia del uncus temporal derecho (Figura 1). Se planteó una EH y se inició aciclovir intravenoso en dosis de 10 $\mathrm{mg} / \mathrm{kg} \mathrm{c} / 8 \mathrm{~h}$. Para el tratamiento de la hipertensión intracraneana se inició sedación con propofol y midazolam, se conectó a ventilación mecánica y se intentó llevar la $\mathrm{PCO}_{2}$ a $30 \mathrm{mmHg}$, se administró sodio hipertónico (3\%) y manitol intravenoso. La punción lumbar (PL) se consideró contraindicada. La paciente persistió en similares condiciones y se instaló un catéter intraparenquimatoso para monitorizar la presión intracraneana (PIC). El monitoreo electroencefalográfico mostró una lentitud generalizada, sin actividad irritativa. Durante las siguientes $24 \mathrm{~h}$ la PIC aumentó progresivamente hasta 60 $\mathrm{mmHg}$, decidiéndose inducir coma barbitúrico. La PIC persistió elevada (30 mmHg). Luego de seis horas de coma barbitúrico con patrón de descarga y supresión en el electroencefalograma (EEG) se consideró fracasado el tratamiento médico. Un equipo multidisciplinario decidió realizar como
Tabla 1. LCR de la paciente en los días tercero y quinto de evolución

\begin{tabular}{|c|c|c|}
\hline & \multicolumn{2}{|c|}{$\begin{array}{l}\text { Días de evolución } \\
\text { (punción lumbar) }\end{array}$} \\
\hline & 3 & 5 \\
\hline Leucocitos $\left(\mathrm{x} \mathrm{mm}^{3}\right)$ & 120 & 180 \\
\hline Neutrófilos (\%) & 40 & 25 \\
\hline Linfocito (\%) & 60 & 75 \\
\hline Proteínas (mg/dL) & 58 & 65 \\
\hline Glucorraquia (mg/dL) & 65 & 50 \\
\hline Glicemia (mg/dL) & 115 & 98 \\
\hline
\end{tabular}

medida de rescate una hemicraniectomía descompresiva. La cirugía consistió en una hemicraniectomía derecha amplia de $12 \mathrm{~cm}^{3}$ asociada a una extensa duroplastia, se obtuvo biopsia del lóbulo temporal derecho, la cual fue informada como una encefalitis necrotizante y hemorrágica. La reacción de polimerasa en cadena (PCR) del tejido encefálico fue positiva para virus herpes simplex. La plaqueta ósea fue almacenada en el banco de huesos.

A las 12 h de la cirugía se efectuó una TAC de control que mostró una hernia del hemisferio

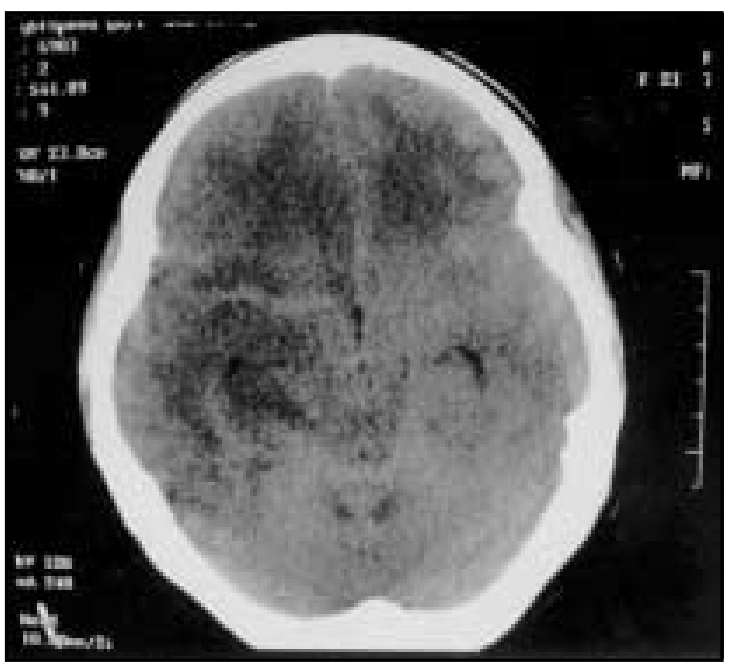

Figura 1. Tomografía computada de encéfalo al ingreso. Se observa una hipodensidad de los lóbulos frontales derecho e izquierdo y temporal derecho. No se observan surcos ni la cisterna perimesencefálica. 


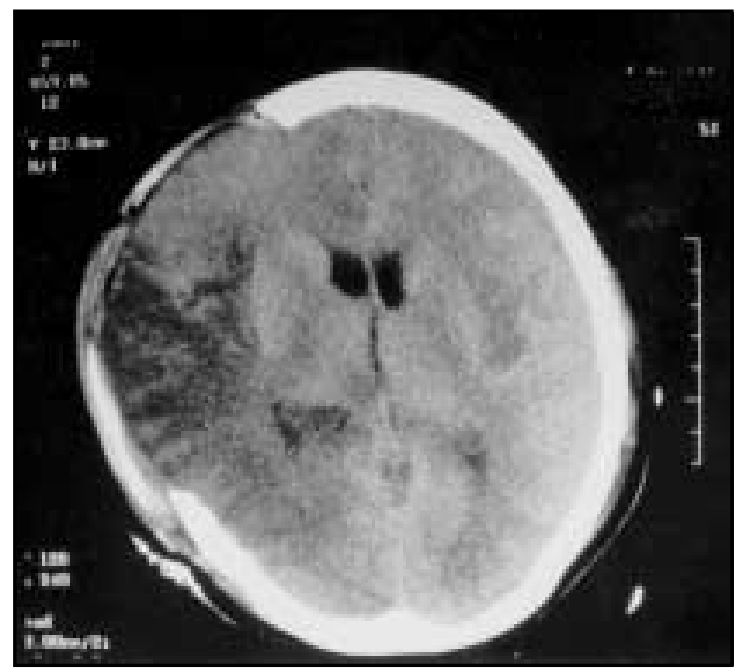

Figura 2. Tomografía computada de encéfalo 12 horas después de la craniectomía descomprensiva. Se observa una hernia encefálica a través de la craniotomía.

derecho a través de la craniectomía, recuperación parcial de la línea media y desaparición de la compresión del mesencéfalo (Figura 2). A los 5 días se realizó una resonancia magnética de encéfalo (RM) que mostró disminución de la hernia encefálica a través de la craniectomía, ventrículos en línea media y una extensa área de señal anormal en las regiones frontal, temporal y parietal derecha y una área menor alterada en las regiones insular y frontal basal izquierda (Figura 3). La paciente recibió aciclovir intravenoso durante 21 días y se debió suspender la fenitoína debido a exantema y síndrome febril.

La evolución clínica fue hacia la recuperación progresiva de la conciencia, alcanzando la vigilia a los 5 días de la craniectomía. La hemiparesia braquio-crural izquierda mejoró lenta y progresivamente, logrando deambular sin dificultad a los dos meses de la cirugía. A los tres meses se reinstaló la plaqueta ósea. A los 10 meses presentó dos crisis parciales complejas, se indicó carbamazepina $200 \mathrm{mg} \mathrm{c} / 12 \mathrm{~h}$, lográndose su control. $\mathrm{Al}$ año de evolución, la paciente se encuentra con una epilepsia controlada, afasia de comprensión moderada y un síndrome frontal desinhibitorio leve. Estas alteraciones cognitivas le permiten una vida autovalente en su casa aunque supervisada por sus padres.

\section{DISCUSIÓN}

La EH es la encefalitis viral más frecuente en nuestro país. Se distribuye universalmente, con una incidencia de 1/500.000 individuos por año. No presenta variación estacional ni diferencia por sexo y compromete a todos los grupos eta$\operatorname{rios}^{1,2,4,5}$. Las alteraciones neuropatológicas presentan una localización macroscópica patognomónica, se compromete bilateralmente, aunque en forma asimétrica, la región orbital de los lóbulos frontales y la región mesial de los lóbulos temporales, posteriormente se observa un compromiso del circuito de Papez, es decir, se observan lesiones que comprometen el trígono, incluso llegando a los cuerpos mamilares ${ }^{6}$. Histopatológicamente se observa una necrosis neuronal y glial, inflamación tisular y hemorragias ${ }^{5}$. En estadios tardíos se observa gliosis y astrocitosis ${ }^{7}$. La tinción con hematoxilina-eosina puede mostrar inclusiones virales intranucleares eosinófilas (tipo A de Cowdry) 8 . Tiene un inicio agudo, en horas, 0 subagudo, en días, y sus manifestaciones clínicas

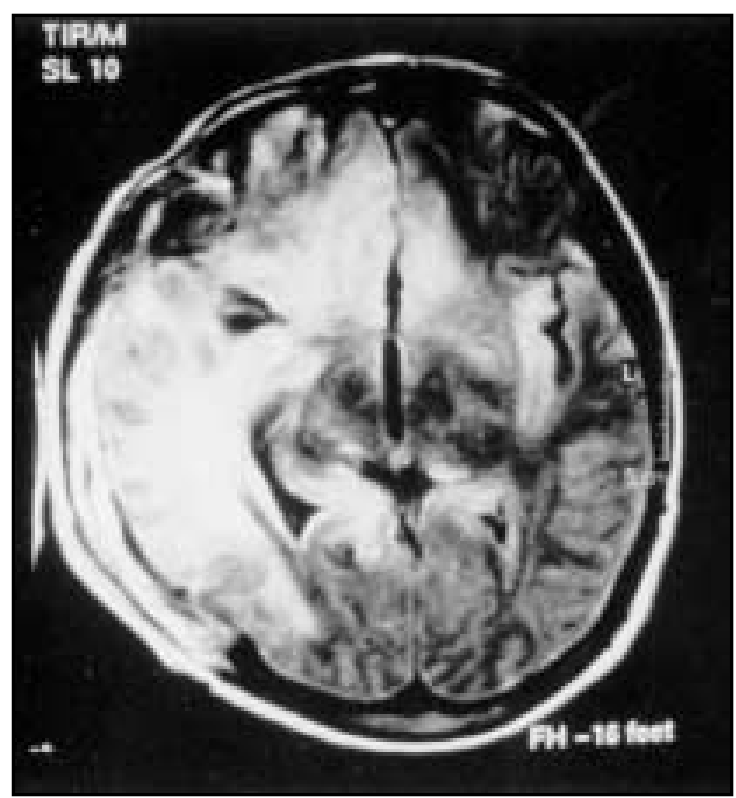

Figura 3. Resonancia magnética del encéfalo al quinto día de la cirugía que muestra una hiperintensidad asimétrica de los lóbulos frontal y temporal bilateralmente. Aún se observa una hernia encefálica a través de la craniotomía derecha. 
son: fiebre, déficit motor, cefalea, alteración de la personalidad, compromiso de conciencia y convulsiones ${ }^{2}$. En días previos, $50 \%$ de los pacientes presentan alucinaciones olfatorias ${ }^{8}$. Es infrecuente la coexistencia con herpes labial. La evolución clínica sin tratamiento con aciclovir, es de curso progresivo hacia el coma y muerte en días ${ }^{1}$.

El estudio del LCR es característico aunque no patognomónico: pleocitosis linfocitaria, aumento de las proteínas, glucorraquia normal y en algunas oportunidades glóbulos rojos frescos ${ }^{5,8}$. Los cultivos virales son positivos sólo en 5\%1. La TAC de encéfalo es anormal en $60 \%{ }^{9}$, pero las alteraciones se detectan días después de iniciados los síntomas $^{10}$. La RM es anormal en $90 \%$ de los casos, incluso en estadios precoces de la enfermedad; la alteración más frecuente es la presencia de una hiperintensidad en las zonas clásicamente comprometidas a nivel macroscópico por esta enfermedad. El electroencefalograma frecuentemente es anormal aunque inespecífico (sensibilidad 84\%, especificidad $32 \%)^{5,9}$. La PCR permite detectar el ADN viral en $24 \mathrm{~h}$. Su sensibilidad y especificidad supera el $95 \%{ }^{11}$. Se han descrito nuevas técnicas de PCR que requieren de sólo $110 \mathrm{~s}^{12}$. La biopsia cerebral es necesaria excepcionalmente, por ejemplo, en pacientes en quienes está contraindicada la PL y no existe certeza diagnóstica. Su sensibilidad es $96 \%$, su especificidad $99 \%$ y sus complicaciones $3 \% 5,13$.

Los pacientes con sospecha de una EH deben ser hospitalizados en unidades de pacientes críticos y además de las medidas generales, se debe iniciar inmediatamente aciclovir intravenoso ${ }^{1,3}$. La dosis recomendada es de $10 \mathrm{mg} / \mathrm{kg}$ cada $8 \mathrm{~h}$, por al menos 10 días ${ }^{1}$.

Los pacientes con EH pueden desarrollar hipertensión intracraneana, su tratamiento se basa en las medidas médicas clásicas: reposo en $30^{\circ}$, evitar el dolor, intubación endotraqueal y conexión a ventilación mecánica, uso de lidocaína intravenosa para las aspiraciones y rotaciones del tubo endotraqueal, cuello en posición media, hiperventilación para obtener una $\mathrm{PaCO}_{2}$ de 30-35 $\mathrm{mmHg}$, manitol y sodio hipertónico intravenosos $^{14}$. Sin embargo, un grupo de pacientes desarrollan una hipertensión intracraneana refractaria a estas medidas y fallecen debido a hernias encefálicas o a una disminución crítica de la presión de perfusión encefálica ${ }^{15}$.
El factor más importante en el pronóstico de los pacientes con una $\mathrm{EH}$ es el inicio precoz de aciclovir intravenoso: antes y después del cuarto día la sobrevida es de 92 y $72 \%$ respectivamente ${ }^{16}$. Factores de mal pronóstico funcional son una escala de Glasgow de ingreso menor a 6 y edad mayor a 30 años $^{3,5}$. El déficit cognitivo en pacientes con una EH es más frecuente y más grave que el de pacientes con otras encefalitis ${ }^{17}$. Los déficits más habituales son: amnesia, afasia, cambios de conducta y personalidad, epilepsia y depresión ${ }^{9}$.

La principal causa de mortalidad es la hipertensión intracraneana refractaria al tratamiento médico. En estos pacientes se ha intentado una medida de rescate: la hemicraniectomía descompresiva. Existen, según nuestro conocimiento, 3 trabajos anecdóticos con 5 pacientes con EH y hemicraniectomía descompresiva publicados en la literatura ${ }^{18-20}$. Schwab y cols, describieron 6 pacientes con hipertensión intracraneana refractaria a tratamiento médico que fueron sometidos a una hemicraniectomía descompresiva, uno de los pacientes presentaba una $\mathrm{EH}$, al año de evolución se había recuperado completamente retornando a su trabajo ${ }^{18}$. Taferner y cols, reportaron 4 pacientes con hipertensión intracraneana refractaria que fueron sometidos a una hemicraniectomía descompresiva, dos de ellos con una $\mathrm{EH}$, en uno se realizó además una lobectomía parcial del lóbulo temporal. Al año, los dos pacientes se encontraban realizando sus actividades habituales ${ }^{19}$. Yan $\mathrm{HJ}$, describió 2 pacientes con $\mathrm{EH}$ que fueron sometidos a una HD debido a un deterioro neurológico progresivo secundario a una hipertensión intracraneana refractaria, los pacientes además fueron sometidos a una lobectomía parcial del lóbulo temporal. Al año, los pacientes presentaban mínimas secuelas neurológicas ${ }^{20}$.

Nuestra paciente ingresó al octavo día de evolución de una EH con signos de una hemia uncal derecha debida a hipertensión intracraneana. Presentaba 2 factores de mal pronóstico: escala de Glasgow de ingreso de 5 e inicio tardío del aciclovir intravenoso. Se iniciaron las medidas clásicas para el tratamiento de la hipertensión intracraneana; luego de $24 \mathrm{~h}$ y debido a la refractariedad en su manejo, se decidió someterla a coma barbitúrico, no lográndose controlar la PIC. En una reunión multidisciplinaria y después de obtener el consentimiento informado de la 
familia se decidió realizar una hemicraniectomía descompresiva del hemisferio derecho. Este procedimiento permitió controlar la PIC, mejorando en días su condición clínica y radiológica. $\mathrm{Al}$ año, la paciente se encuentra con una epilepsia parcial compleja controlada, afasia de comprensión moderada y un síndrome frontal desinhibitorio; estas alteraciones cognitivas le permiten una vida autovalente en su casa, aunque supervisada por sus padres. Es el convencimiento de los autores que de no haberse realizado este procedimiento la

\section{REFERENCIAS}

1. López M, Melado P. Encefalitis herpética. Cuad Neurol 2002; 26: 27-37.

2. Whitley RJ, Soong SJ, Lunnemann C, Lu C, Pazin G, ALFORD CA. NIAID collaborative antiviral study group. Herpes simplex encephalitis. Clinical assessment. JAMA 1982; 247: 317-20.

3. Whitley RJ, GnANn JR. Acyclovir: a decade later. $\mathrm{N}$ Engl J Med 1992; 327: 782-9.

4. Ross KL. Encephalitis. Clin Neurol 1999; 17: 81333.

5. WhitLey RJ. Herpes simplex virus. En: Scheld WM, Whitley RJ, Durack DT, eds. Infections of the central nervous system. Philadelphia. LippincottRaven 1997; 73-89.

6. BARINGER JR. Herpes simples virus infections of the nervous system. En: Vinken PJ, Bruyn GW, eds. Handbook of Clinical Neurology. Amsterdam. North-Holland Publishing Company 1978; 145-59.

7. WhitLey RJ, GNANN JW. Viral encephalitis: familiar infections and emerging pathogens. Lancet 2002; 359: 507-13.

8. BARINGER JR. Herpes simplex virus encephalitis. En: Davis LE, Kennedy PG, eds. Infectious diseases of the nervous system. Oxford. ButterworthHeinemann 2000; 139-64.

9. McGrath N, Anderson NE, Croxson MC, Powel KF. Herpes simplex encephalitis treated with acyclovir: diagnosis and long term outcome. J Neurol Neurosurg Psychiatry 1997; 63: 321-6.

10. Burke JW, Mathews VP, Eister AD, Ulmer JL, McLean FM, Davis SB. Contrast-enhanced magnetization transfer saturation imaging improves MR detection of herpes simplex encephalitis. AJNR 1996; 17: 773-6. paciente hubiese progresado hacia la muerte cerebral.

\section{CONCLUSIÓN}

Basados en la literatura y en este caso clínico, creemos que es posible rescatar pacientes con una EH e hipertensión intracraneana refractaria a tratamiento médico con una hemicraniectomía descompresiva.

11. LAKEMAN FD, WHITLEY RJ. NIAID-collaborative antiviral study group. Diagnosis of herpes simplex encephalitis: application of polymerase chain reaction to cerebrospinal fluid from brain-biopsied patients and correlation with disease. J Infect Dis 1995; 171: 857-63.

12. Hofgartner WT, Huhmer AF, Landers JP, Kant JA. Rapid diagnosis of herpes simplex encephalitis using microchip electrophoresis of PCR products. Clin Chem 1999; 45: 2120-8.

13. Moorawetz RB, Whitley RJ, Murphy DM. Experience with brain biopsy for suspected herpes encephalitis: a review of 40 consecutive cases. Neurosurg 1983; 12: 654-7.

14. Meliado P, Sandoval P. Hipertensión intracraneana. Cuad Neurol 2001; 21: 30-40.

15. BARNETT GH, Ropper AH, Romeo J. Intracranial pressure and outcome in adult encephalitis. J Neurosurg 1988; 68: 585-8.

16. WhiтLEY RJ. Viral encephalitis. N Engl J Med 1990; 323: 242-50.

17. Hokkanen L, Poutiainen E, Valanne L, Salonen O, IIVANAINEN M, LAUNES J. Cognitive impairment after acute encephalitis: comparison of herpes simples and other aetiologies. J Neurol Neurosurg Psychiatry 1996; 61: 478-84.

18. Schwab S, Junger E, Spranger M, Dorfler A, Albert F, Steiner HH et AL. Craniectomy: An aggressive treatment approach in severe encephalitis. Neurology 1997; 48: 412-7.

19. Taferner E, Pfausler B, Kofler A, Spiss H, EngelharDT K, Kamprl A ET al. Craniectomy in severe, lifethreatening encephalitis: a report on outcome and long-term prognosis of four cases. Intensive Care Med 2001; 27: 1426-8.

20. Yan HJ. Herpes simplex encephalitis: the role of surgical decompression. Surg Neurol 2002; 57: 20-4. 